九州大学学術情報リポジトリ

Kyushu University Institutional Repository

\title{
THE FAMILY MYCHOTHENIDAE OF JAPAN (COLEOPTERA)
}

Sasaji, Hiroyuki

https://doi.org/10.5109/2528

出版情報 : ESAKIA. Special Issue 1, pp.65-75, 1990-04-20. Entomological Laboratory, Faculty of Agriculture, Kyushu University バージョン :

権利関係 : 


\title{
THE FAMILY MYCHOTHENIDAE OF JAPAN (COLEOPTERA)
}

\author{
HiROYuki SASAJI \\ Biological Laboratory, Fukui University, Fukui, 910 Japan
}

\begin{abstract}
The family Mychothenidae (Coleoptera) of Japan is revised. Five new species are described in this paper: Mychothenus hirashimai (Okinawa), Bystodes flavoapicalis (Okinawa), Bystodes kidoi (Kyushu), Bystodes yaeyamensis (Ishigaki-jima), and Idiophyes uenoi (Okinawa). A key to the genera and species of the Japanese Mychothenidae is also provided.
\end{abstract}

In 1978, I proposed a subfamily Mychotheninae for some round and small-sized genera in the family Endomychidae auct., with the descriptions of 3 new species. After more careful comparative study, I concluded that this group was more desirable to be separated as a distinct family rather than included within the family Endomychidae (Sasaji, 1987). The difinition of the Mychothenidae is shown in later lines. Up to now, 8 species of the Mychothenidae are hitherto known from Japan including the Ryukyus, and 5 new species are added in this paper. On this occasion, I will provide the key to all the Japanese genera and species of the family.

Before going further, my hearty thanks are due to Mr. T. Ueno and Mr. K. Kido, who sent me valuable specimens. I wish to dedicate this small paper to Prof. Emer. Y. Hirashima.

\section{Family MYCHOTHENIDAE}

Mychotheninae Sasaji, 1978, Mem. Fac. Educ., Fukui Univ., Ser. II, (2) (pt. 1) : 8 (type-genus : Mychothenus Strohecker, 1953).

Mychothenidae Sasaji, 1987, Entom. J. Fukui, (1) : 44, 47 (status nov.).

This family almost entirely corresponds with the subfamily Mychotheninae in Sasaji (1978) which was proposed as a subfamily of the Endomychidae.

Diagnosis Body hemispherical or short oval ; small, usually less than $2.5 \mathrm{~mm}$; dorsum pubescent. Head capsule transverse oval, frontoclypeal suture distinct. Tentorium consisting of a pair of thin lateral arms, which are connected with each other by a corpotentorial bridge at base, and are not fused with each other in middle. Antenna moderate in relative length, usually 9- or lo-segmented, rarely 11-segmented, with loosely articulated S-segmented club. Front coxal cavity widely open posteriorly. Middle coxal cavity closed outwardly by the connection of meso- and metasterna. Mesepimeron triangular, and not reaching to middle coxal cavity. Abdomen exposed 6 visible sternites ; 1st visible stemite without femoral line. Elytral epipleuron flat, relatively wide. Elytral apex usually with special sculptures, e. g. a pair of foveolae or transverse groove in male. Tarsal 
formula usually 3-3-3, rarely 3-4-4 ; penultimate tarsal segment simple, not distinctly lobed below or dilated apically.

\section{Key to the Genera and Species of the Mychothenidae of Japan}

1(25) Body outline hemispherical or short oval, strongly covex above. Antenna 9- or 10segmented, with a distinct 3-segmented club. Tarsi trimerous in all legs. Sutural furrow of elytra very fine and not extending besides scutellum.

2(19) Basal side of pronotum strongly sinuate, distinctly produced posteriorly at middle part. Transverse furrow along basal margin of pronotum absent. Elytra without punctate-striae.

3(14) Antenna lo-segmented.

4(7) Pronotum without lateral sulci. Elytral epipleuron relatively short, ending at posterior margin of 3rd abdominal sternite (Mychothenus).

5(6) Foveolae at elytral apex in male small and indistinct (Fig. 2-D). Margination of pronotal side distinctly widening anteriorly (Fig. 2-B). Elytral punctures relatively strong and dense ; elytral hairs shorter (Fig. 2-F). Prosternal carinae suddenly narrowing anteriorly at anterior part. 1.25-1.45 mm …...... Mychothenus asiaticus Sasaji

6(5) Foveolae at elytral apex in male large and very deep (Fig. 2-C). Margination of pronotal side narrow throughout. Elytral punctures finer and sparser ; elytral hairs long. Prosternal carinae straightly narrowing apically. $1.30-1.40 \mathrm{~mm}$

Mychothenus hirashimai sp. nov.

7(4) Pronotum with a pair of lateral sulci at middle of each half. Elytral epipleuron relatively long, reaching to 5 th abdominal sternite (Bystodes).

8(11) Lateral sulci of pronotum long, reaching near anterior margin of pronotum (Fig. 3C). Prosternal carinae curved and divergent both anteriorly and posteriorly (Fig. 3-G). Margination of pronotal side widening anteriorly.

9(10) Body outline somewhat longer. Elytral punctures strong and dense ; elytral hairs short (Fig. 3-I). Antenna slender and long. Body yellowish brown to reddish brown, sometimes pronotum and sutureal area of elytra blackish. 1.7-2.2 mm

Bystodes orbicularis (Gorham)

10(9) Body outline more rounded. Elytral punctures much finer and sparser ; elytral hairs very long and strongly erect (Fig. 3-H). 1.25-1.40 mm …... Bystodes yaeyamensis sp. nov.

11(8) Lateral sulci of pronotum short, reaching about half a pronotal length. Margination of pronotal lateral side narrow throughout. Prosternal carinae straightly convergent anteriorly (Fig. 3-F).

12(13) Dorsum blackish brown, elytra with a pair of yellowish brown markings which are oval and situated at posterior $2 / 5$ to $1 / 10$ of elytral length. Head and pronotum sometimes reddish. Pronotal side strongly and smoothly arcuate. Foveolae at elytral apex in male simple and rounded. Tenth antennal segment longer than wide.

$1.30-1.55 \mathrm{~mm}$

Bystodes flavoapicalis sp. nov.

13(12) Dorsum almost uniformly reddish brown. Pronotal lateral side rather weakly arcuate with somewhat angulate basal comer (Fig. 3-B). Apical area of elytra very deeply and triangularly foveolate, and provided with a transverse elevation at each lateral side of foveola (Fig. 3-E). Tenth antennal segment much wider than long. $1.30-1.50 \mathrm{~mm}$

Bystodes kidoi sp. nov. Antenna g-segmented. 
15(16) Pronotum without lateral sulci (Dialexia). Body outline nearly hemispherical ; blackish brown with a large round reddish brown area at centre of each elytron ; border of the marking indistinct. $1.5 \mathrm{~mm}$

Dialexia hisanoi Sasaji

16(15) Pronotum with lateral sulci which are about half a pronotal length (Dexialia).

17(18) Dorsum almost uniformly yellowish brown to blackish brown; sometimes pronotum and/or posterior area of elytra reddish but without distinct marking. Pronotal sides rather weakly arcuate. Scutellum slightly wider than long. 1.30$1.50 \mathrm{~mm}$

Dexialia minor (Chûjô)

18(17) Head and pronotum dark reddish brown ; elytra blackish brown with a pair of large yellowish brown markings which are round, situated from apical $2 / 5$ to $1 / 10$ of elytral length. Pronotal sides very strongly arcuate. Scutellum strongly transverse, 3 times as wide as long. $1.40 \mathrm{~mm}$

Dexialia spectabilis Sasaji

19(2) Basal side of pronotum very weakly sinuate; almost straight at middle part ; transverse deep furrow running along basal margin of pronotum. Elytra with distinct punctate-striae. Elytral epipleuron wide and long, almost reaching elytral apex (Idiophyes).

20(21) Lateral sulci of pronotum rather weakly convergent anteriorly each other, with a long inner branch which is much longer than half a sulcus. Prosternal process with a pair of distinct carinae. 1.3-1.8 $\mathrm{mm}$

Idiophyes niponensis (Gorham)

21(20) Lateral sulci of pronotum very strongly convergent anteriorly each other, with an inner branch which is about half a sulcus. Prosternal process without carinae.

22(23) First interstice of elytra distinctly wider than 2nd. Eighth and 9th antennal segments not wider than long. Modification of elytral apex in male distinct, transversely linear. Lateral side of prontum very strongly arcuate ; basal corner rounded. $1.50-1.75 \mathrm{~mm}$

Idiophyes boninensis Sasaji

23(22) First interstice of elytra slightly wider than 2nd. Eighth and 9th antennal segments wider than long; apical segment with an obliguely truncate apical side. Modification of elytral apex indistinct. Lateral side of pronotum weakly arcuate ; basal corner somewhat angulate. $1.60-1.75 \mathrm{~mm} \ldots \ldots \ldots \ldots \ldots \ldots$........... Idiophyes uenoi sp. nov.

25(1) Body outline oblong oval, rather weakly convex above. Antenna 1l-segmented, with a loosely articulated club. Tarsal formula 3-4-4. Each elytron with a distinct sutural fullow which arcuately extends along scutellum (Asymbius). Yellowish brown. Pronotum strongly transverse, lateral sides angulately produced at a little behind the middle ; lateral sulci shorter than half a pronotal length; basal furrow of pronotum distinct with a pair of deep foveolae at lateral ends. $1.5 \mathrm{~mm}$

Asymbius foveicollis Chûjô et Kiuchi

Mychothenus asiaticus Sasaji, 1978

Japanese name : Daen-tentôdamashi

(Fig. 2-B, D, F)

Specimens examined. 14 exs. Fukui Pref. : Oshima. Fukuoka Pref. : Mt. Hikosan. Distribution. Japan (Honshu, Kyushu). 

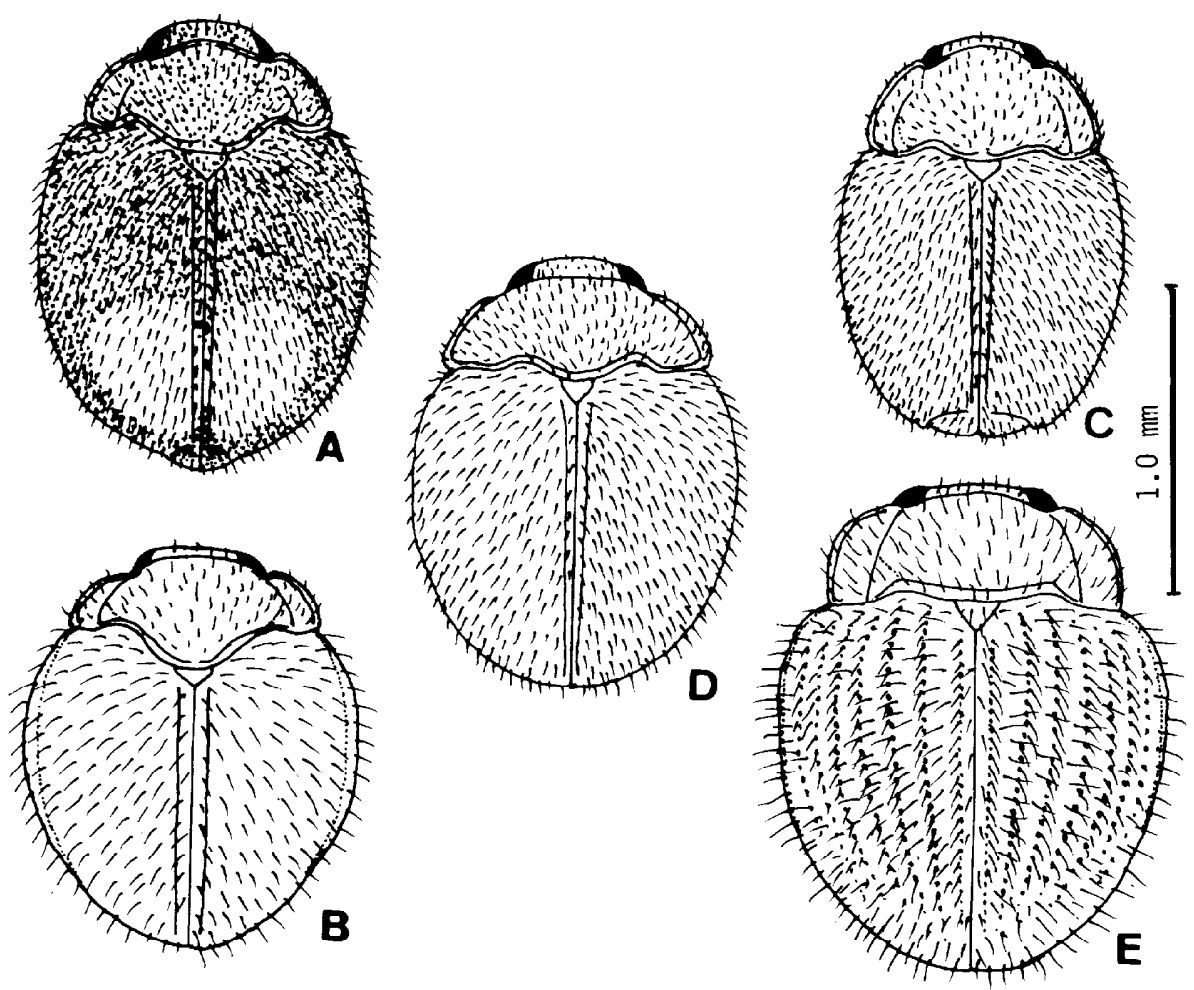

Fig. 1. Dorsal outlines. A:Bystodes flavoapicalis sp. nov. B : Bystodes yaeyamensis sp. nov. $\mathrm{C}$ : Bystodes kidoi sp. nov. D : Mychothenus hirashimai sp. nov. E : Idiophyes uenoi sp. nov.

\section{Mychothenus hirashimai sp. nov.}

Japanese name :Okinawa-daen-tentôdamashi

(Fig. 1-D, Fig. Z-A, C, E, G, H)

Male. Short oval, 1.4 times as long as wide. Head, pronotum and underside dark reddish brown ; elytra blackish brown; antennae, mouth parts and legs yellowish brown.

Head about $3 / 5$ as wide as pronotal width. Frons gently convex, very finely and sparsely punctate ; frontoclypeal furrow nearly straight. Antenna nearly as long as head width ; each of antenna1 segments as shown in Fig. 2-H ; 3rd elongate ; each of 4th to 7th transverse ; 8th distinctly longer than wide. Pronotum strongly transverse, 2.3 times as wide as the length of median line. Pronotal disc relatively finely and sparsely punctate, with rather long, thin, suberect hairs. Basal side of pronotum strongly produced posteriorly at middle part and deeply marginate. Lateral side of pronotum (Fig. 2-A) strongly arcuate ; narrowly marginate throughout ; slightly narrowing both anteriorly and posteriorly ; basal corner of pronotum rounded. Scutellum transverse triangle, almost impunctate. Elytra nearly as wide as long; elytral side smoothly arcuate. Elytral punctures distinctly stronger and denser than those on pronotum, but distinctly finer and sparser than in $M$. asiaticus (Fig. 2-E, F). A fine stria represented along the suture. Elytral apex (Fig. 2-C) provided with a very deep and rather large round foveola on each apex. Prosternal carinae straight and distinctly convergent anteriorly (Fig. 2-G). 
Female. Elytral apex simple without foveolae.

Variation. Often elytra dark reddish brown as like as pronotum. Elytra reddish brown as like as pronotum. Elytra reddish brown with darker sutural and lateral areas in some paratypes.

Body length : 1.30-1.40 (1.40) mm; width : 0.92-1.00 (1.00) mm; L/W : 1.33-1.40 (1.40). Those of the holotype are in parentheses.

Distribution. Ryukyus (Okinawa-jima).

Holotype(ơ): Sueyoshi, Naha-shi, Okinawa-jima, 5. vii. 1987, T. Ueno leg., preserved in the Collection of Entomological Laboratory, Kyushu University, Fukuoka.

Allotopotype ( $(q)$ : The same data as the holotype.

Paratopotypes : $10^{\text {T }}$ the same data as the holotype ;10 3o\%, Sueyoshi, Naha-shi, 11. x. 1988, H. Sasaji leg. ;19, Sueyoshi, Naha-shi, 8. vii. 1987, T, Ueno leg.

PARATYPeS : 10 3oo, Yona, Okinawa-jima, 16-17. iii. 1988, T. Ueno leg.

Remarks. The present new species is very closely related to the preceding species, but distinguishable from the latter by the characters shown in the key.

Bystodes orbicularis (Gorham, 1887)

Japanese name :Marugata-tentôdamashi

(Fig. 3-1)

SPecimes eXamined. 19, Senju-ga-hara, Chûgashi, Nikko-shi, Tochigi Pref., 7. vii. 1984, N. Morishima leg. ; 19, Nikko, 9. vi. 1935 ; 19, Yunomata, Oohata-machi, Aomori Pref., 9. vii. 1956, K. Morimoto leg., '19, Shimajima, Nagano Pref. ; 16. viii. 1984, M. Saitô leg. ;19, Yashagaike, Fukui Pref., 21. vi. 1961, H. Sasaji leg.

Distribution. Japan (Honshu).
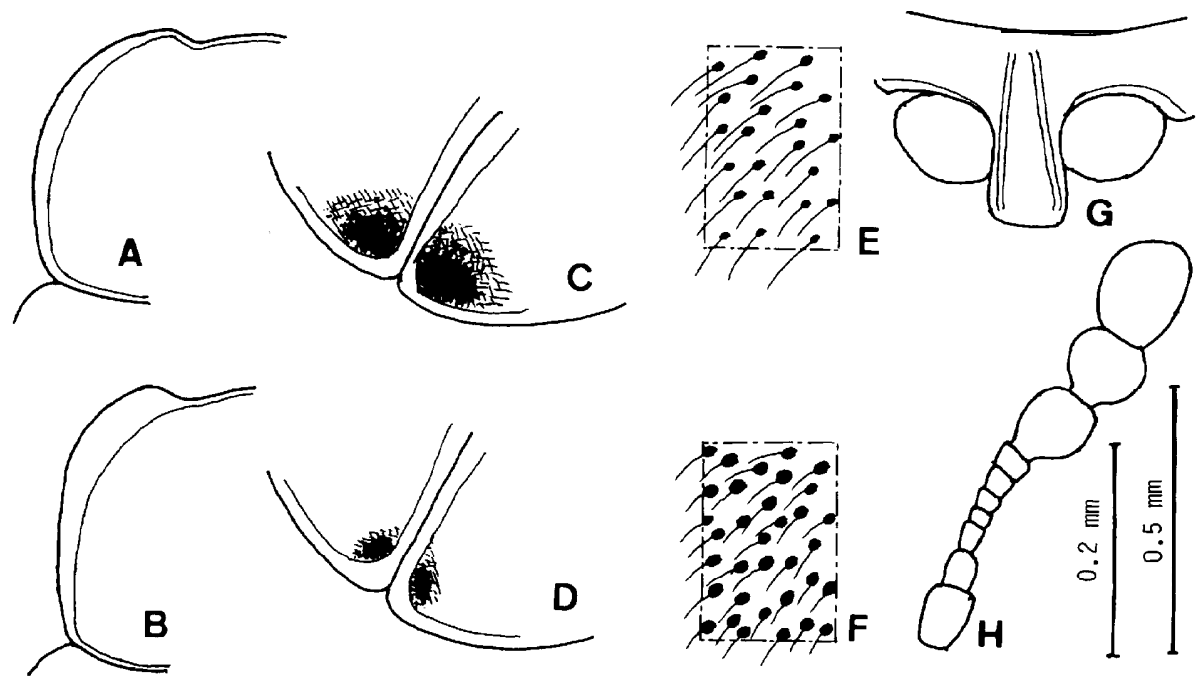

Fig. 2. Mychothenus spp. A, C, E, G, H : M.hirashimai sp. nov. ; B, D, F : M.asiaticus Sasaji. A, B : Lateral areas of pronota, dorso-lateral view ; C, D : Apical areas of elytra, dorso-lateral view ; E, F : Punctures and hairs of central areas of each elytron ; G : Prosternal process ; H : Antenna. 0.5 $\mathrm{mm}$ scale is applied to C, D; $0.2 \mathrm{~mm}$ scale is to the remains. 


\section{Bys todes Ravoapicalis sp. nov.}

Japanese name :Kimon-marutentôdamashi

(Fig. 1-A, Fig. 3-A, D, F, J)

Male. Short oval, about 1.4 times an long as wide. Head and pronotum blackish red-brown; elytra blackish brown, each elytron with an oval pale yellowish brown marking which is situated from apical $2 / 5$ to $1 / 10$ of elytral length and rather widely separated from lateral side of elytron. Antenna yellowish brown with blackish brown club. Mouth parts and legs yellowish brown; underside of body dark reddish brown. Dorsal pubescence pale yellowish white.

Head $3 / 5$ as wide as pronotal width ; eyes relatively small, interocular distance $5 / 8$ as much as head width. Frons weakly convex and very finely punctate. Frontoclypeal furrow slightly arcuate. Antenna nearly as long as head width. Each of antennal segments as shown in Fig. 3-J ; 3rd twice as long as wide; 8th and 9th longer than wide. Pronotum about twice as wide as the length in median line. Lateral sulcus (Fig. 3-A) short, about $1 / 2$ as long as pronotal length at its part ; inner branch
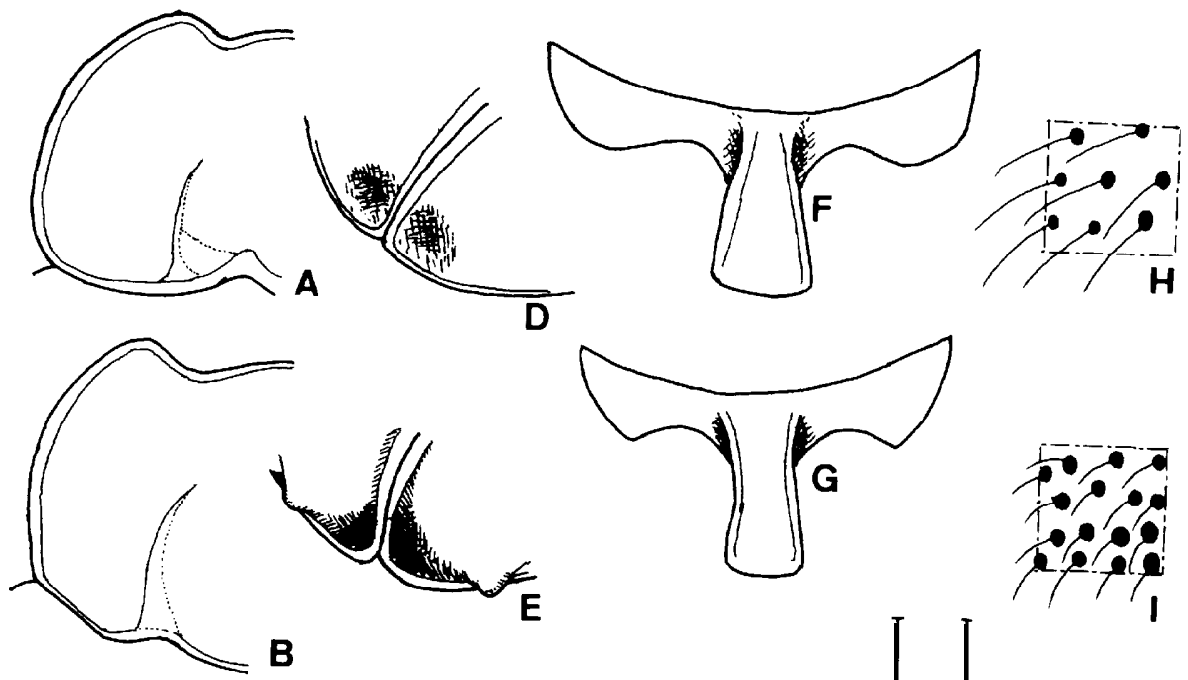

B
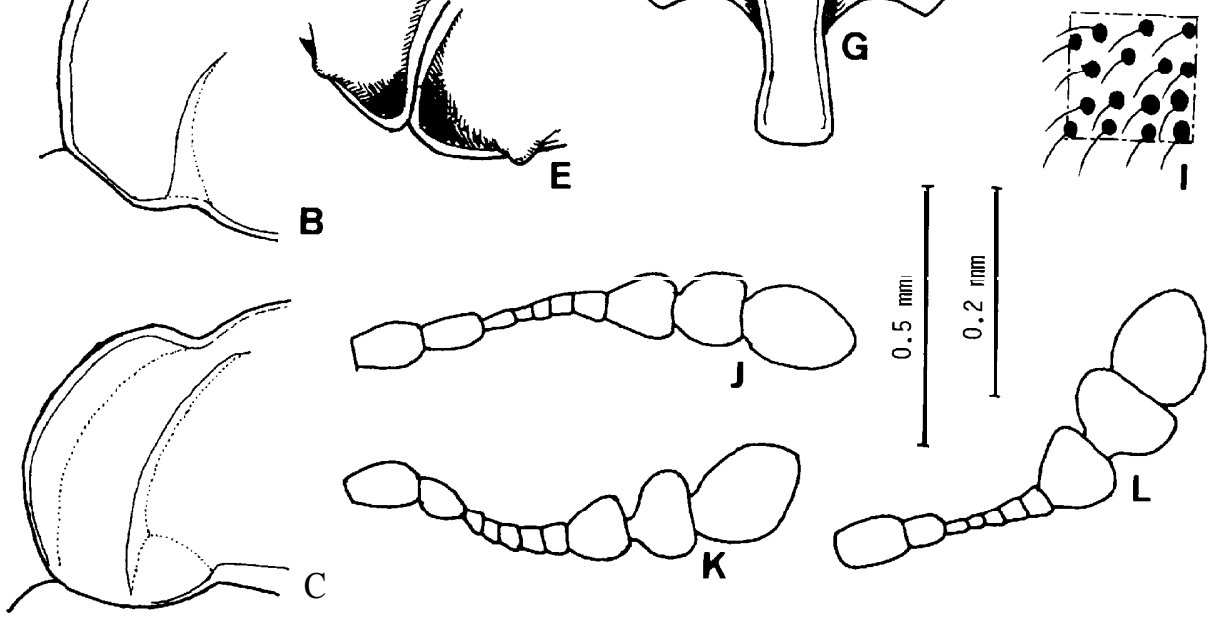

Fig. 3. Bystodes spp. A, D, F, J : B. flavoapicalis sp. nov. B, E, K : B. kidoi sp. nov. C, G, H, L :B. yaeyamensis sp. nov. I : B. orbicularis (Gorham). A-C : Lateral areas of pronota, dorso-lateral view ; D, E : Apical areas of elytra, dorso-lateral view ; F, G: Prosternal processes ; H, I : Punctures and hairs of central areas of each elytron; J-L : Antennae. $0.5 \mathrm{~mm}$ scale is applied to D, E ; $0.2 \mathrm{~mm}$ scale is to the remains. 
of the sulcus very short and strongly oblique. Lateral side of pronotum strongly arcuate. Pronotal disc very finely and irregularly punctate. Scutellum transverse triangle, 1.5 times as wide as long. Elytra 1.1 times as long as wide ; with strongly arcuate sides. Elytral disc strongly and densely punctate ; elytral hairs coarse and suberect. Apical foveolae of elytra shallow and round (Fig. 3-D). Prosternal carinae straight and strongly convergent anteriorly (Fig. 3-F).

Female. Elytral apex simple.

Variation. Ground colour of dorsum often deep brownish black. Apical markings of elytra larger than the holotype in some paratypes.

Body length : 1.30-1.52 (1.45) mm ; width : 0.95-1.05 (1.02) mm;L/W : 1.37-1.45 (1.41). Those of the holotype are in parentheses.

Distribution. Ryukyus (Okinawa-jima).

HoLotype (ơ ) : Sueyoshi, Naha-shi, Okinawa-jima, 5. vii. 1987, T. Ueno leg., preserved in the Collection of Entomological Laboratory, Kyushu University, Fukuoka.

Allotopotype (Q) : The same data as the holotype.

Paratopotypes : 399 , the same data as the holotype ;10 19, Sueyoshi, Naha-shi, 8. vii. 1988, T. Ueno leg. ; 10̛', Sueyoshi, Naha-shi, 11. x. 1988, H. Sasaji leg.

Paratypes : $20^{7}$ o $29 \%$, Yona, Okinawa-jima, 16-17. iii. 1988, T. Ueno leg.

Remarks . This new species is easily separable from the known species of the genus Bystodes by the distinct elytral markings. Colour pattern of this species is similar to that of Dexialiaspectabilis Sasaji, but the pronotum is darker and the antennae are lo-segmented in this species.

\section{Bystodes kidoi sp. nov. \\ Japanese name :Kido-marutentôdamashi}

(Fig. 1-C, Fig. 3-B, E, K)

Male. Short oval, about 1.5 times as long as wide. Dorsum blackish brown ; antennae yellowish brown with dark brown club ; mouth parts and legs yellowish brown ; underside of body blackish brown. Dorsal pubescence golden brown.

Head $3 / 5$ as wide as pronotal width ; eyes small, situated strongly transversely, $2 / 3$ as long as wide in frontal view ; interocular distance 0.65 as much as head width. Frons almost flat, slightly convex, shining with minute punctures. Frontoclypeal furrow straight ; clypeus narrow, parallelsided, about $2 / 3$ as wide as interocular distance. Antenna somewhat longer than head width. Each of antenna1 segments as shown in Fig. 2-K ; 8th triangle, as long as wide ; 9th much wider than long. Pronotum twice as wide as the length in median line. Lateral side of pronotum rather weakly arcuate. Lateral sulcus of pronotum about $3 / 5$ as long as pronotal length at its part ; strongly curved inwards (Fig. 3-B). Surface of pronotum strongly shining with very fine punctures. Scutellum subpentagonal, wider than long. Elytra slightly longer than wide, with rather weakly arcuate sides. Elytral punctures very strong and coarse ; interstice between punctures weakly convex ; elytral hairs also coarse. Sutural furrow of elytra rather distinct except near scutellum. Elytral apex complicately sculptured (Fig. 3-E) ; foveolae very deep, large and transverse triangle ; anterior area from foveola linearly elevated and ridged, of which lateral part angulately raised. Prosternal carinae neary as in $\boldsymbol{B}$. flavoapicalis.

Female. Elytral apex simple.

Variation. In a paratype, dorsal coloration paler in general.

Body length : 1.30-1.50 (1.30) mm ; width : 0.87-1.05 (0.87) mm ; L/W : 1.40-1.50 (1.49). Those of the holotype are in parentheses.

Distribution. Japan (Kyushu). 
Holotype (ơ ): Jô-yama, Fukuoka Pref., Japan, 6. x. 1986, K. Kido leg., preserved in the Collection of Entomological Laboratory, Kyushu University, Fukuoka.

Allotopotype (q): Jô-yama, Fukuoka Pref., 10. x. 1986, K. Kido leg.

Paratopotypes : $10^{7}$, Jô-yama, 30. viii. 1986, K. Kido leg. ; 19 , the same data as the allotopotype.

Remarks. From the related species of the genus Bystodes, this is distinguishable by the characters shown in the key. In having the uniformly browinish dorsum and the short pronotal sulci, this new species is very similar to Dexialia minor (Chajô) in their general appearances, but the latter has 9segmented antennae and the denser elytral punctures.

\section{Bys todes yaeyamensis sp. nov.}

Japanese name :Kenaga-marutentôdamashi

(Fig. 1-B, Fig. 3-C, G, H, L)

Female. Hemispherical, 1.2 times an long as wide. Dorsum orange brown ; antennae yellowish brown with black club ; mouth parts and underside of body also orange brown; legs somewhat yellowish. Dorsal pubescence pale orange brown.

Head 0.55 as wide as pronotal width ; eye relatively large, its longitudinal diameter longer than transverse diameter in frontal view. Frons weakly convex with minute punctures. Frontoclypeal furrow straight. Antenna nearly as long as head width ; each of antennal segments as shown in Fig. 3-L. Antennal club stout, longer than the remaining segments taken together ; 9th large, distinctly wider than long. Pronotal sides very strongly arcuate and very strongly narrowing anteriorly ; lateral margination with double lines, extreme one very narrowly and inner one rather widely separated from lateral margin and narrowing basally (Fig. 3-C). Lateral sulcus of pronotum almost reaching to anterior margin of pronotum, strongly arcuate and outer line of sulcus strongly edged, inner branch of sulcus short, and triangle area surrounded by the inner branch and the main line of sulcus wider than long (Fig. 3-C). Pronotal surface very sparsely and very finely punctate. Scutellum trasverse triangle. Elytra wider than long, with strongly arcuate sides. Elytral margin distinctly marginated with furrow until near apex. Elytral punctures relatively fine and sparse ; elytral hairs very long and erect (Fig. 3-H). Prosternal carinae weakly arcuate, divergent both anteriorly and posteriorly (Fig. 3-G).

Male. unknown.

Body length : 1.25-1.40 (1.25) mm ; width : 1.05-1.13 (1.05) mm ; L/W :1.19-1.25 (1.19). Those of the holotype are in parentheses.

DistRibution. Ryukyus (Ishigaki-jima).

Holotype (P): Omoto-dake, Ishigaki-jima, 4-5. viii. 1988, T. Ueno leg., preserved in the Collection of Entomological Laboratory, Kyushu University, Fukuoka.

Allotopotype and Paratopotype : 299, the same data as the holotype.

REMARKs. This new species is closely related to B.orbicularis from Japan, but it is separable as shown in the key. It is also related to B. taiwanensis from Formosa, but the latter has the narrower pronotal margination and the narrower and shorter antennal club.

Dialexia hisanoi Sasaji, 1978

Japanese name : Benimon-marugatatentadamashi

Specimens EXAmined. $10^{7} 19$ (holotype and paratype), Iwaya, Katsuyama-shi, Fukui Pref., 11. iii. 1976, K. Hisano leg. 
Distribution. Japan (Honshu).

\author{
Dexialia minor (Chajô, 1941) \\ Japanese name :Hime-marugatatentôdamashi
}

Specimens examined. $60^{\top} 0^{\top} 12$ $\$$ from the following localities. Hokkaido : Mt. Hakodate. Fukui Pref. : Kinjô-tôge; Kyôgatake, Ohno-shi ; Makidani, Mt. Hino; Mt. Aoba ; Nôgô-hakusan ; Naramata. Nara Pref. : Ohdaigahara. Fukuoka Pref. : Mt. Hikosan.

Distribution. Japan (Hokkaido, Honshu, Shikoku, Kyushu).

D exialia spectabilis Sasaji, 1984

Japanese name :Atomon-marugatatentôdamashi

SPecimen eXamined. 10 (holotype), Kasedo citrus grove, Nagashima, Kagoshima Pref., 14. vii. 1977, S. Nakao et al. leg.

Distribution. Japan (Nagashima I., in Kagoshima Pref.).

Idiophyes niponensis (Gorham, 1874)

Japanese name :Ko-marugatatentôdamashi

(Fig. 4-C E)

Specimens examined. $120^{7} 1399$ from the following localities. Chiba Pref. : Inage. Fukui Pref. : Aoshima I. Wakayama Pref. : Chihaya-jô. Fukuoka Pref. : Mt. Jô-yama ; Mt. Tachibana. Yakushima :Shiratani-Unsuitôge ( 1 \&, 18. vii. 1989, N. Narukawa leg.).

Distribution. Japan (Honshu, Shikoku, Kyushu, Yakushima-new record).

Idiophyes boninensis Sasaji, 1978

Japanes name :Ogasawara-ko-marugatatentôdamashi

(Fig. 4-B, I)

SPecimens EXAmined. $80^{\top} 0^{\top} 8$ 우 from the following localities (incl. holotype). Chichi-jima: Oogiura ; Kiyose ; Komagari ; Oomura.

Distribution. Ogasawara Is. (Chichi-jima).

\title{
Idiophyes uenoi sp. nov.
}

Japanese name : Ueno-ko-marugatatentadamashi

(Fig. 1-E, Fig. 4-A, D, G, H)

Male. Short oval, 1.3 times as long as wide. Uniformly pale orange brown. Head 1/2 as wide as pronotal width ; eye relatively small, well prominent laterally ; inner ocular margin weakly arcuate; frons gently convex with sparse and very fine punctures. Frontoclypeal furrow straight. Antenna 1.2 times as long as head width. Each of antennal segments as shown in Fig. 4-G. Eighth and 9th nearly as wide as long ; 10th longer than wide, with an obliquely truncate apex. Pronotal side moderately strongly arcuate, weakly narrowing at basal part in dorsal view. Distance between lateral sulcus and lateral margin distinctly wideninsg anteriorly (Fig. 4-A) ; inner branch of pronotal sulcus short and strongly incline inwards. Pronotal disc finely and sparsely punctate. Scutellum triangle with a few punctures. Elytral punctate-striae nearly as in $I$. boninensis but Ist interstice not distinctly wider than 2nd. Foveola of elytral apex transversely linear, shallow and narrow in 

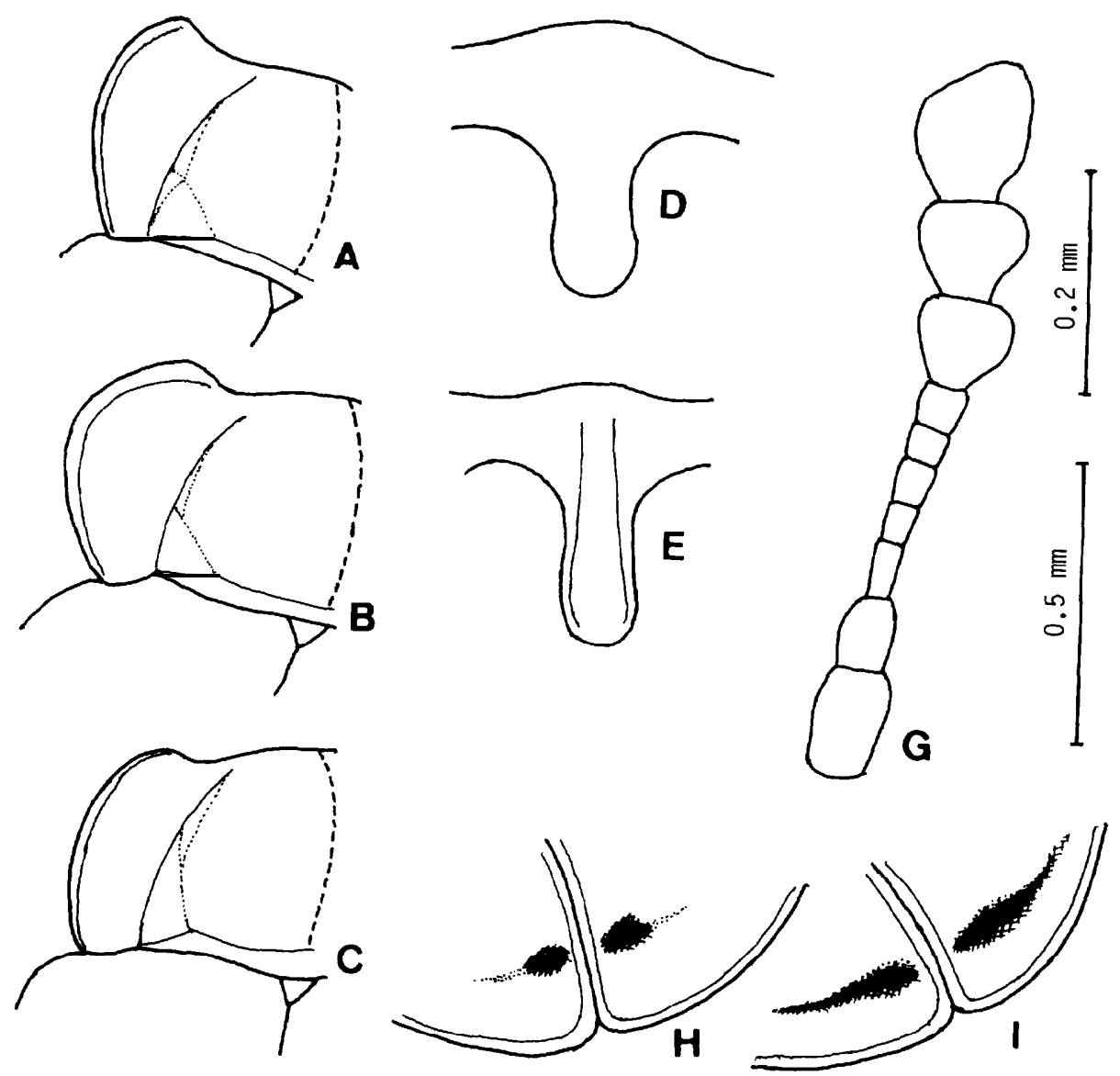

Fig. 4. Idiophyes spp. A, D, G, H : I. uenoi sp. nov. B, I : I. boninensis Sasaji. C, E : I. niponensis (Gorham). A-C: Lateral areas of pronota, dorso-lateral view; D, E: Prosternal processses; G : Antenna ; H, I : Apical areas of elytra, dorso-lateral view. $0.2 \mathrm{~mm}$ scale is applied to D, E, G ; 0.5 $\mathrm{mm}$ scale is to the remains.

transverse length. Prosternum without carinae, longitudinally raised at median line.

Female. Elytral apex simple.

Body length : 1.62-1.78 (1.62) mm ; width : 1.25-1.35 (1.25) mm ; L/W : 1.30-1.35 (1.30). Those of the holotype are in parentheses.

Distribution . Ryukyus (Okinawa-jima).

Holotype (0) : Sueyoshi, Naha-shi, Okinawa-jima, 8. vii. 1987, T. Ueno leg., preserved in the Collection of Entomological Laboratory, Kyushu University, Fukuoka.

Allotopotype ( $($ ) : The same data as the holotype.

Paratopotypes: $60^{7}$ or 1 , the same data as the holotype ;2, o ơ, 599, Sueyoshi, Naha-shi, 5. vii. 1987, T. Ueno leg.

Remarks. The present new species is more closely related to $I$. boninensis from the Ogasawara Islands (=the Bonin Islands) than to $I$. niponensis from Japan proper, this fact suggests that the biogeographical similarity between the Ryukyu Islands and the Ogasawara Islands. From $I$. 
boninensis this species is distinguished by the characters shown in the key.

Asymbius foveicollis Chûjô et Kiuchi, 1974

Japanese name : Tokara-sesuji-tentbdamashi

Specimen eXAmined. 19, Nakano-shima, Tokara Is., 1. v. 1971, M. Sakai leg.

DistRibution. Ryukyus (Nakano-shima in Tokara Is.).

\section{References}

(For literature before 1977, see Sasaji, 1978 and 1983).

Sasaji, H., 1978. Notes on the Japanese Endomychidae, with an establishment of a new subfamily (Coleoptera). Mem. Fac. Educ., Fukui Univ., Ser. II, (28) (pt. 1) : 1-31.

1980. A synopsis of the Japanese Endomychidae. Coleopt. News, (49) :1-4; (50) :1-6; (51): $1-4 ;(52): 1-5$. (In Japanese).

1983. Family Endomychidae. Check-list of Coleoptera of Japan, No. 21, 8 pp.

- 1984. Contribution to the taxonomy of the superfamily Cucujoidea of Japan and her adjacent districts, II. Mem. Fac. Educ., Fukui Univ., Ser. II. (34) (pt. 2) : 21-63.

1987. On the higher classification of the Endomychidae and their relative families (Coleoptera). Entom.J. Fukui, (1) : 44-51. (In Japanese with English synopsis). 